\title{
Surgical Site Infection (SSI) in the National Referral General Hospital of Ndjamena (Chad): Survey about Risk Factors
}

\author{
Hassan Mahamat Ali ${ }^{1,2}$, Yeri Esther Hien ${ }^{2}$, Cheikna Zongo², Denis Erbi ${ }^{2}$, Ali Haroun Hissein ${ }^{2}$, \\ François Tapsoba², Abacar Mahamat Tahir², Brahim Adoum Ahamt' ${ }^{2,3}$, Yves Traore², \\ Aly Savadogo ${ }^{2}$
}

\author{
${ }^{1}$ Sectoral Program to Fight AIDS and Sexually Transmitted Infections (PSLS/IST), N'Djamena, Chad \\ ${ }^{2}$ Laboratoire de Biochimie et d'Immunologie Appliquées (LaBIA), Université Joseph Ki-Zerbo de Ouagadougou, Ouagadougou, \\ Burkina Faso \\ ${ }^{3}$ Laboratoire de Recherche, de Diagnostic et d'Expertises Scientifiques (Labo REDES) de N’Djamena, N'Djamena, Chad \\ Email: *yriestherhien@yahoo.fr
}

How to cite this paper: Ali, H.M., Hien, Y.E., Zongo, C., Erbi, D., Hissein, A.H., Tapsoba, F., Tahir, A.M., Ahamt, B.A., Traore, Y. and Savadogo, A. (2021) Surgical Site Infection (SSI) in the National Referral General Hospital of Ndjamena (Chad): Survey about Risk Factors. Journal of Biosciences and Medicines, 9, 1-11.

https://doi.org/10.4236/jbm.2021.95001

Received: January 17, 2021

Accepted: May 4, 2021

Published: May 7, 2021

Copyright $\odot 2021$ by author(s) and Scientific Research Publishing Inc. This work is licensed under the Creative Commons Attribution International License (CC BY 4.0).

http://creativecommons.org/licenses/by/4.0/

\begin{abstract}
The risk to develop an infection after surgery depends on several factors. Those factors may be interdependent or not, depending on the nature of the surgery and the general condition of the patient. The aim of the present study was to identify the factors involved in the occurrence of the Surgical Site Infections (SSI) in the National referral general hospital of N'djamena (Chad). We first realized an interview in the emergency services and in the general surgery of the hospital. The information collected allowed us to draw up survey sheets. An investigation was then conducted on 152 patients who had surgery and were hospitalized during the study period. The frequency of the SSI was $33.6 \%(51 / 152)$. The main risk factors that we identified were the duration of hospitalization, the category of the hospitalization room, the urgent aspect of the surgical intervention, the patient's nutritional status and the associated diseases with diabetes, which was present in $52.38 \%(11 / 21)$ of cases of associated pathologies. Analysis of the antibiotic prophylaxis administered to patients showed that ciprofloxacin was more effective in SSI prevention. Indeed, this antibiotic showed the fewest cases of infection with only $1.9 \%$ of patients having developed SSI. Our results show a very high frequency of SSI at the National referral general hospital of $\mathrm{N}$ 'djamena. Poor hospital practices and factors associated to patients seem to be the most factors implicated in the SSI.
\end{abstract}

\section{Keywords}

Surgical Site Infections, Risk Factors, Nutritional Status, Associated Diseases, 
Chad

\section{Introduction}

Surgical Site Infections (SSI) are generally localized infections. But these infections can spread to organs far from the surgical site sharing or not the same pathogen germ [1] [2]. It is a complication that arises after surgery. Therefore, they do not occur before surgery, nor even in incubation [3]. Host commensal flora is generally responsible for these infections due to the poor immunity of the host, but microorganisms circulating in the hospital environment can also be involved in this infection [4]. Bacteria involved in these infections exhibit antibiotic resistance profiles [5]. There are risk factors that are involved in these infections. These risk factors can be classified into modifiable and non-modifiable risk factors [6] and can be interdependent or isolated [7]. Hospital environment is conducive to the spread of these infections, especially when hygienic conditions are unfavorable [8]. Other factors such as the failure to respect asepsis practices seem to increase the risk of these infections [9]. A recent survey carried out by some African researchers in 25 African countries revealed that patients who undergo surgery in African hospitals are two times more likely to die from post-operative complications than those in other hospitals on other continents [10]. The SSI are therefore a major component of the post-operative complications in Africa.

Chadian hospitals, like other African hospitals, are also facing surgical site infections, but there is almost few research conducted on that topic. To our knowledge, very few studies have been carried out on the factors favoring infections in Chadian hospitals. The aim of this study was to determine the prevalence of SSI and the factors involved in the occurrence of those infections within the $\mathrm{Na}$ tional referral general hospital of Ndjamena, in order to find a prevention strategy.

\section{Materials and Methods}

\subsection{Setting and Population}

This prospective study was performed from July to November 2018 in the surgery service of the National referral general hospital of Ndjamena. Analyses were done in the laboratory of the National referral general hospital of Ndjamena in collaboration with the Laboratory of Biochemistry and Applied Immunology (LaBIA) of the University Joseph KI-ZERBO. Patients hospitalized after surgery and undergoing antibiotic treatment were included in the study.

\subsection{Data Collection}

We first realized an interview with the staff of the emergency services and those of general surgery of the hospital. The information collected allowed us to draw up survey sheets. An investigation was then conducted on 152 patients who had 
surgery and were hospitalized during the study period.

\subsection{Data Treatment and Analysis}

The data were analyzed using Sphinx 5, which is a tool for creating and analyzing online questionnaires, forms and surveys. It allows to design questionnaires, process and analyze data and present results. The chi-square test was used for comparisons and every value was considered statistically significant for $p \leq 0.05$.

\section{Results}

\subsection{SSI Frequency}

One hundred and fifty-two (152) patients underwent surgery during the period of our investigation, in the surgical and emergency departments of the Hospital. The patients were aged from 16 to 86 years with an average age of 36.1. Men were predominant in the study population (111/152) with a proportion of 73.03\% giving the sex ratio of 2.7. Among the 152 patients who underwent surgery and were interned in the surgical and the emergency department of the Hospital, 51 patients presented SSI giving an overall incidence of 33.6\%. The SSI patients' average age was 37.9 years; the minimum age was 22 and the maximum was 86 . Among the SSI patients $78.43 \%(40 / 51)$ were men (Table 1), the sex ratio was 3.6.

\subsection{Risk Factors Analysis}

To determine the factors involved in the onset of infections, different factors were analyzed such as the duration of hospitalizations, the nature of the surgery and their urgent aspect (scheduled or not), the nutritional status of the patients, the category of the hospitalization room, the presence of associated pathologies, the order of wound dressings and antibiotic prophylaxis received after surgery.

\subsection{Factors Related to Patient's Status}

\section{Patients' nutritional status}

The patients' nutritional status has been identified on the basis of their Body Mass Index (BMI). That BMI have been defined by WHO and was obtained by dividing the patient's weight (in $\mathrm{kg}$ ) by the square of his height $(\mathrm{m})$. Analysis of

Table 1. Prevalence of SSI after surgery depending on gender.

\begin{tabular}{cccc}
\hline & \multicolumn{2}{c}{ Sex } & TOTAL \\
\cline { 2 - 3 } & Females & Males & \\
\hline Presence of an SSI & $26.8 \%(11)$ & $36.0 \%(40)$ & $33.6 \%(51)$ \\
YES & $73.2 \%(30)$ & $64.0 \%(71)$ & $66.4 \%(101)$ \\
NO & $100 \%(41)$ & $100 \%(111)$ & $100 \%(152)$ \\
\hline
\end{tabular}


the relation between patients' nutritional status and the occurrence of an SSI presented in Table 2 shows a significant dependence with $p=0.0103$.

\section{Associated pathologies}

We analyzed the pathologies associated to the occurrence of SSI. The most current pathologies in SSI patients were diabetes, hypertension, renal failure and infectious syndrome. These pathologies were presented respectively in $11 / 21$ (52.3\%), 5/21 (23.8\%), 1/21 (4.7\%) and 4/21 (19.2\%) of SSI cases. Diabetes was the most frequent pathology among SSI patients. The analysis of the relationship between the associated pathologies and the occurrence of SSI is presented in Table 3. Our results showed that $100 \%(21 / 21)$ of patients with SSI had an associated pathology $(p=0.01)$.

\subsection{Factors Related to Health Centers}

\section{Hospital stay duration}

Patients who underwent surgery spent an average of 13.5 days in hospital, with a minimum of 4 days and a maximum of 21 days in hospital, for those who did not develop an SSI. The patients who develop an SSI spent an average of 37 days with a minimum of 27 days and a maximum of 77 days in hospital. Patients with SSI spent more time in hospital than other patients $(p=0.05)$ (Table 4$)$.

\section{Categories of hospitalization rooms}

There are different categories of hospitalization rooms that are available after surgical acts. The first category rooms are single rooms with large space and air conditioning. These rooms are clean and there is no disturbing neighborhood. The second and third categories have two or three beds without air conditioning with promiscuity between patients. Most of the patients were hospitalized in the third category (114/152); only four (4) patients were hospitalized in the first category (Table 5). The SSI were more observed in second and third categories

Table 2. Comparison of the patients' nutritional status (Body Mass Index: BMI).

\begin{tabular}{cccccccc}
\hline & \multicolumn{9}{c}{ Nutritional status of the patient (BMI) } & \multirow{2}{*}{ TOTAL } & $P$-value \\
\cline { 2 - 4 } & IMC $\leq 18$ & $18<\mathrm{IMC}<25$ & $25 \leq \mathrm{IMC}<30$ & IMC $\geq 30$ & unknown & & \\
\hline Presence of SSI & & & & & & & \\
YES & $100 \%(11)$ & $22.4 \%(17)$ & $100 \%(4)$ & $100 \%(2)$ & $28.8 \%(17)$ & $33.6 \%(51)$ & \\
NO & $0.0 \%(0)$ & $77.6 \%(59)$ & $0.0 \%(0)$ & $0.0 \%(0)$ & $71.2 \%(42)$ & $66.4 \%(101)$ & $p=0.0103$ \\
TOTAL & $100 \%(11)$ & $100 \%(76)$ & $100 \%(4)$ & $100 \%(2)$ & $100 \%(59)$ & $100 \%(152)$ & \\
\hline
\end{tabular}

Table 3. Presence of associated pathologies and the occurrence of SSI.

\begin{tabular}{ccccc}
\hline & \multicolumn{2}{c}{ Presence of SSI } & \multirow{2}{*}{ TOTAL } & $p$-value \\
\cline { 2 - 3 } & YES & NO & & \\
\hline Presence of associated pathologies & & & & \\
YES & $100 \%(21)$ & $22.9 \%(30)$ & $33.6 \%(51)$ & \\
NO & $0.0 \%(0)$ & $77.1 \%(101)$ & $66.4 \%(101)$ & $p=0.0001$ \\
TOTAL & $100 \%(21)$ & $100 \%(131)$ & $100 \%(152)$ & \\
\hline
\end{tabular}


Table 4. Hospital stay duration among patients with SSI.

\begin{tabular}{ccccc}
\hline \multirow{2}{*}{ Hospitalization duration per day } & \multicolumn{2}{c}{ Occurrence of SSI } & \multirow{2}{*}{ TOTAL } & $p$-value \\
\cline { 2 - 3 } & YES & NO & & \\
\hline $\mathbf{1 0}$ & $2.0 \%(1)$ & $85.1 \%(86)$ & $57.2 \%(87)$ & \\
{$[10-20]$} & $43.1 \%(22)$ & $13.9 \%(14)$ & $23.7 \%(36)$ & \\
{$[20-30]$} & $29.4 \%(15)$ & $1.0 \%(1)$ & $10.5 \%(16)$ & $p=0.0005$ \\
$>30$ & $25.5 \%(13)$ & $0.0 \%(0)$ & $8.6 \%(13)$ & \\
TOTAL & $100 \%(51)$ & $100 \%(101)$ & $100 \%(152)$ &
\end{tabular}

Table 5. Occurrence of SSI according to the category of hospitalization rooms.

\begin{tabular}{|c|c|c|c|c|c|}
\hline & \multicolumn{3}{|c|}{ Level of hospitalization } & \multirow{2}{*}{ TOTAL } & \multirow{2}{*}{$P$-value } \\
\hline & Category 1 & Category 2 & Category 3 & & \\
\hline \multicolumn{6}{|c|}{ Presence of SSI } \\
\hline YES & $0.0 \%(0)$ & $17.6 \%(6)$ & $39.5 \%(45)$ & $33.6 \%(51)$ & \multirow{3}{*}{$p=0.02$} \\
\hline NO & $100 \%(4)$ & $82.4 \%(28)$ & $60.5 \%(69)$ & $66.4 \%(101)$ & \\
\hline TOTAL & $100 \%(4)$ & $100 \%(34)$ & $100 \%(114)$ & $100 \%(152)$ & \\
\hline
\end{tabular}

while no infection was observed in patients hospitalized in the first category ( $p=$ $0.02)$

\subsection{Factors Related to the Medical Act}

\section{Nature and urgent aspect of the surgical intervention}

Analysis of the nature of surgery showed that patients with digestive surgery present more SSI than others $(p=0.0041)$ (Table 6). Among the patients concerned by this survey, only 20 had their intervention programmed whereas the other 132 were in an emergency case. SSI were more frequent in patients whose interventions were made in emergency $(p=0.0167)$ (Table 7).

Occurrence of SSI according to the order of bandages and antibiotic prophylaxis

Bandages are changed during the postoperative stay. Our results showed that most of the infections occur after the second bandage (Table 8). The order of the bandage was a factor involved in the occurrence of SSI $(p=0.01)$. In surgery department, each patient after the chirurgical act should automatically receive one of the four molecules used for the antibiotic prophylaxis. Those molecules were ceftriaxone, ampicillin, amoxicillin or ciprofloxacin. We showed that most of the patients have received ceftriaxone $(40.2 \%(61 / 152))$ and ampicillin $(32.8 \%$ (50/152)). However, $43.3 \%$ of patients who have developed an SSI had received ceftriaxone, $39.2 \%$ ampicillin and $15.6 \%$ amoxicillin; only $1.9 \%$ had received ciprofloxacin (Table 9).

\section{Discussion}

The frequency of SSI found in this survey at 33.6\%, is higher than those obtained 
Table 6. Comparison of the nature of surgery practiced and the occurrence of SSI in operated patients.

\begin{tabular}{ccccc}
\hline & \multicolumn{2}{c}{ Presence of SSI } & \multirow{2}{*}{ TOTAL } & $p$-value \\
\cline { 2 - 3 } & YES & NO & & \\
\hline Type of the surgery & & & & \\
Digestive & $58.8 \%(30)$ & $47.5 \%(48)$ & $51.3 \%(78)$ & \\
Urinary & $11.8 \%(6)$ & $12.9 \%(13)$ & $12.5 \%(19)$ & \\
Orthopedic & $15.7 \%(8)$ & $14.8 \%(15)$ & $15.1 \%(23)$ & $p=0.415$ \\
Others & $13.7 \%(7)$ & $24.8 \%(25)$ & $21.1 \%(32)$ & \\
Total & $100 \%(51)$ & $100 \%(101)$ & $100 \%(152)$ & \\
\hline
\end{tabular}

Table 7. Comparison of the nature of the surgery (urgent or programmed) and the occurrence of an SSI in the operated patients.

\begin{tabular}{|c|c|c|c|c|}
\hline & \multicolumn{2}{|c|}{ Character of surgery } & \multirow{2}{*}{ TOTAL } & \multirow{2}{*}{$p$-value } \\
\hline & Urgent & Programmed & & \\
\hline \multicolumn{5}{|c|}{ Presence of SSI } \\
\hline YES & $37.1 \%(49)$ & $10.0 \%(2)$ & $33.6 \%(51)$ & \multirow{3}{*}{$p=0.167$} \\
\hline NO & $62.9 \%(83)$ & $90.0 \%(18)$ & $66.4 \%(101)$ & \\
\hline TOTAL & $100 \%(132)$ & $100 \%(20)$ & $100 \%(152)$ & \\
\hline
\end{tabular}

Table 8. Occurrence of the SSI according to the order of bandages.

\begin{tabular}{ccccc}
\hline & \multicolumn{2}{c}{ Presence of SSI } & \multirow{2}{*}{ TOTAL } & $P$-value \\
\cline { 2 - 3 } & YES & NO & & \\
\cline { 2 - 3 } Number of bandages & & & & \\
$1^{\text {st }}$ & $3.9 \%(2)$ & $78.2 \%(79)$ & $53.3 \%(81)$ & \\
$2^{\text {nd }}$ & $51.0 \%(26)$ & $13.9 \%(14)$ & $26.3 \%(40)$ & \\
$3^{\text {rd }}$ & $41.2 \%(21)$ & $5.9 \%(6)$ & $17.8 \%(27)$ & $p=0.0001$ \\
$4^{\text {th }}$ & $3.9 \%(2)$ & $2.0 \%(2)$ & $2.6 \%(4)$ & \\
TOTAL $^{\text {TO }}$ & $100 \%(51)$ & $100 \%(101)$ & $100 \%(152)$ & \\
\hline
\end{tabular}

Table 9. Antibiotic treatment and occurrence of SSI.

\begin{tabular}{ccc}
\hline Type of antibiotics used & Proportion of patients & Presence of SSI \\
\hline Ceftriazone & $40.1 \%(61)$ & $43.1 \%(22)$ \\
Ampicilline & $32.9 \%(50)$ & $39.2 \%(20)$ \\
Amoxicilline & $17.8 \%(27)$ & $15.7 \%(8)$ \\
Ciprofloxacine & $9.2 \%(14)$ & $2.0 \%(1)$ \\
Total & $100 \%(152)$ & $100 \%(51)$ \\
\hline
\end{tabular}

by other studies carried out in Morocco by Bouzid et al., 2015 and in Central Republic of Africa by Bercion et al. 2007 [11] [12]. These studies found a preva- 
lence of $16.0 \%$ and $18.0 \%$ respectively at Morocco and in central republic of Africa. The prevalence found in our study is also higher than that found by Nwankwo et al. 2016 in Nigeria and in the meta-analysis study carried out by Ngaroua et al., 2016. Nwankwo et al. found a frequency of $25.2 \%$ and Ngaroua et al. found a frequency range between $6.8 \%-26 \%$ depending on the country and the type of study [13] [14]. This high incidence of SSI could be explained by the lack of monitoring and prevention program of these infections in developing countries [12]. It could also be explained by the development of multi-resistant bacteria in the hospital, which infect surgical wounds despite the administration of antibiotic therapy [15]. The hygienic conditions in hospital and overcrowding in hospital rooms might explain the high frequency found in our study. This could be illustrated by the fact that all the patients presenting an SSI were hospitalized in the second and third categories with 45 patients out of 51 who were hospitalized in the third category. Interestingly no patient in the first category showed SSI even if there are minorities.

Analysis of risk factor in our study showed that age does not appear as a risk factor for the occurrence of SSI $(P=0.2)$. The slightly elevated rate of SSI $(22 / 51$ SSI cases) observed in patients aged 29 to 39 years could be explained by the type of surgery performed in these patients. Bouzid et al. 2015, have also reported similar observations in Morocco in 2015 [12]. Gender also does not appear to be a risk factor in this survey $(p=0.36)$ as reported by Bouzid and al. in his survey in Morocco. The lower frequency of SSI in women could be explained by the fact that women were in minority in the study population. This could be explained by the fact that there is no obstetric surgery in this hospital.

In opposition to gender and sex, nutritional status appears as a risk factor for the occurrence of SSI. Patients with a BMI $<18$ and those who have a BMI $\geq 25$ are exposed to the risk to develop an SSI. Other studies have also reported that the nutritional status may be a risk factor for SSI [13]. Nutritional status directly influences the disorganization of the immune system [16], creating therefore a deficiency of the immune system. Riana, 2009 in her work on nutrition and infections reported that malnutrition leads to general immune deficiency. That might promote the development and the proliferation of human commensal germs, and facilitate the occurrence of SSI [17]. Associated pathologies are also a risk factor for SSI. Among the associated pathologies, diabetes appears to be the main risk factor (11/21 case of associated pathologies). These results could be explained by the fact that the associated pathologies like diabetes create an immunosuppression, promoting the appearance of SSI [18] [19].

The high prevalence of SSI in digestive surgery could be explained by endogenous contamination due to the large commensal flora of the digestive tract. Digestive surgery wounds are easily accessible to the touch of the human hand. This can be done either by the patient himself or by his entourage. In addition, digestive surgery most often requires the installation of drainage. Changing or removing drains by nurses can lead to contamination [20] [21]. This is consistent with the observation that the occurrence of SSI was most observed between 
the $2 \mathrm{nd}, 3 \mathrm{rd}$ and 4 th dressing received after surgery. This result is similar to that found by Bouzid et al. 2015 in Morocco who reported that SSI occurs between the 2nd and the 3rd bandage changing [12]. In accordance with these data the duration of hospitalization appears to be a risk factor for SSI. Ours results are similar to those reported by Nwankwo et al. 2014 and Keita et al., 2016 who reported that the duration of hospitalization is a risk factor for SSI. The same observations were also found by Cheng et al., 2015 [14] [22] [23]. Many hypotheses could explain the association between the occurrence of an SSI and the duration of hospitalizations. The contamination may come through dirty hands during bandaging, the hospital environment, the patient's itself and the relatives who accompany the patient or even from the visitors.

The nature of the surgery was not a risk factor for the occurrence of SSI. But urgent surgical situations can promotes SSI as described in several studies [21]. In our investigation, emergency surgery was associated with the occurrence of SSI. There are many reasons that can explain this significant relationship found in our survey. In fact, patients seen in emergency situations are less prepared before surgery. On the contrary, those who are scheduled undergo very rigorous preoperative preparations in accordance with the recent WHO recommendations. This is in agreement with the fact that patients with scheduled surgery are those with clean surgery where the occurrence of SSI is low, as described in the literature [13] [24].

\section{Conclusion}

In our study population and among SSI patients, men were predominant and average age of patients was 37.9 years. Analysis of risk factor showed that, patients' nutritional status was significantly associated to the occurrence of SSI. In addition, $100 \%(21 / 21)$ of patients with SSI had an associated pathology. The factors related to health centers like hospital stay duration and category of hospitalization room have showed a significant association to the occurrence of SSI. The nature of the surgical intervention and their urgent aspect were also associated to SSI. The same observations have been made for the order of bandages with the majority of infections observed at the second bandage. Antibiotic prophylaxis analysis showed that ciprofloxacin was more effective in SSI prevention with only $1.9 \%$ of SSI in patients with ciprofloxacin treatment. In conclusion, our study showed a high frequency of SSI (33.6\%). The main risk factors are human factors and hospital hygiene. It is therefore necessary to take concrete measures to limit these bad attitudes: first at the level of hospital staff, secondly at the level of patients and finally at the level of those who accompany patients and even visitors, to reverse the trend.

\section{Author's Contributions}

Study conception and design: HMA and ZC. Data collection and analysis: HMA. Coordination of the survey and correction of the manuscript: $\mathrm{ZC}$ and YEH. The 
final version has been corrected by AS, AT and YEH.

\section{Acknowledgements}

Authors are grateful to the National referral general hospital of Ndjamena for the working facilities and technical assistance. We are also thankful to Laboratoire de Biochimie et d'Immunologie Appliquées of the University Joseph ki-Zerbo, Ouagadougou (Burkina Faso) for the working facilities and assistance in the redaction of this article.

\section{Conflicts of Interest}

The authors declare no competing interests.

\section{References}

[1] Malone, D.L., Genuit, T., Tracy, J.K., Gannon, C. and Napolitano, L.M. (2002) Surgical Site Infections: Reanalysis of Risk Factors. Journal of Surgical Research, 103, 89-95. https://doi.org/10.1006/jsre.2001.6343

[2] Leșe, M. and Micu-Chis, R.D. (2018) The Microbiology of Surgical Infections. International Journal of Applied Science and Technology, 8, 48-56. https://doi.org/10.30845/ijast.v8n3p5

[3] Anderson, D.J., Podgorny, K., Berríos-Torres, S.I., Bratzler, D.W., Dellinger, E.P., Greene, L., Nyquist, A.-C., Saiman, L., Yokoe, D.S., Maragakis, L.L. and Kaye, K.S (2014) Strategies to Prevent Surgical Site Infections in Acute Care Hospitals: 2014 Update. Infection Control \& Hospital Epidemiology, 35, 605-627. https://doi.org/10.1086/676022

[4] Korol, E., Johnston, K., Waser, N., Sifakis, F., Jafri, H.S., Lo, M. and Kyaw, M.H. (2013) A Systematic Review of Risk Factors Associated with Surgical Site Infections among Surgical Patients. PLoS One, 8, e83743. https://doi.org/10.1371/journal.pone.0083743

[5] Ouchar Mahamat, O., Lounnas, M., Hide, M., Dumont, Y., Tidjani, A., Kamougam, K., Abderrahmane, M., Benavides, J., Solassol, J., Bañuls, A.-L., Jean-Pierre, H. and Carrière, C., Godreuil, S. (2019) High Prevalence and Characterization of ExtendedSpectrum ß-Lactamase Producing Enterobacteriaceae in Chadian Hospitals. BMC Infectious Diseases, 19, Article No. 205. https://doi.org/10.1186/s12879-019-3838-1

[6] Florschutz, A.V., Fagan, R.P., Matar, W.Y., Sawyer, R.G. and Berrios-Torres, S.I. (2015) Surgical Site Infection Risk Factors and Risk Stratification. Journal of the American Academy of Orthopaedic Surgeons, 23, S8-S11. https://doi.org/10.5435/JAAOS-D-14-00447

[7] Colás-Ruiz, E., Del-Moral-Luque, J.A., Gil-Yonte, P., Fernández-Cebrián, J.M., Alonso-García, M., Villar-del-Campo, M.C., Durán-Poveda, M. and RodríguezCaravaca, G. (2018) Incidencia de infección de sitio quirúrgico y factores de riesgo en cirugía de recto. Estudio de cohortes prospectivo. Cirugía Española, 96, 640-647. https://doi.org/10.1016/j.ciresp.2018.06.007

[8] Lukuke, H.M., Kasamba, E., Mahuridi, A., Nlandu, R.N., Narufumi, S., Mukengeshayi, A.N., Malou, V., Makoutode, M. and Kaj, F.M. (2017) L'incidence des infections nosocomiales urinaires et des sites opératoires dans la maternité de l'Hôpital Général de Référence de Katuba à Lubumbashi en République Démocratique du 
Congo. Pan African Medical Journal, 28, Article 57.

https://doi.org/10.11604/pamj.2017.28.57.9866

[9] Okasha, H. (2019) Risk Factors and Key Principles for Prevention of Surgical Site Infections. IntechOpen2019.

https://www.intechopen.com/books/surgical-infections-some-facts/risk-factors-and -key-principles-for-prevention-of-surgical-site-infections https://doi.org/10.5772/intechopen.85284

[10] Biccard, B.M., Madiba, T.E., Kluyts, H.-L., Munlemvo, D.M., Madzimbamuto, F.D., Basenero, A., Gordon, C.S., Youssouf, C., Rakotoarison, S.R., Gobin, V., Samateh, A.L., Sani, C.M., Omigbodun, A.O., Amanor-Boadu, S.D., Tumukunde, J.T., Esterhuizen, T.M., Le Manach, Y., Forget, P., Elkhogia, A.M., Mehyaoui, R.M., Zoumeno, E., Ndayisaba, G., Ndasi, H., Ndonga, A.K.N., Ngumi, Z.W.W., Patel, U.P., Ashebir, D.Z., Antwi-Kusi, A.A.K., Mbwele, B., Sama, H.D., Elfiky, M., Fawzy, M.A. and Pearse, R.M., on Behalf of the African Surgical Outcomes Study (ASOS) Investigators (2018) Perioperative Patient Outcomes in the African Surgical Outcomes Study: A 7-Day Prospective Observational Cohort Study. The Lancet, 391, 1589-1598. https://doi.org/10.1016/S0140-6736(18)30001-1

[11] Bercion, R., Gaudeuille, A., Mapouka, P.A., Behounde, T. and Guetahoun, Y. (2007) Infections du site opératoire dans le service de chirurgie orthopédique de l'hôpital communautaire de Bangui, République centrafricaine. Bulletin de la Société de pathologie exotique, 100, 197-200.

[12] Bouzid, J., Bouhlal, A., Chahlaoui, A., Aababou, S., Aarab, M. and Jari, I. (2015) Détermination de la prévalence des Infections du site opératoire chez les opérés de 1 hôpital Mohamed V de Meknès. International Journal of Innovation and Scientific Research, 14, 198-207.

[13] Ngaroua, J.E., Ngah, T.B. and Djibrilla Y. (2016) Incidence des infections du site opératoire en Afrique sub-saharienne: Revue systématique et méta-analyse. Pan African Medical Journal, 24, Article 171. https://doi.org/10.11604/pamj.2016.24.171.9754

[14] Nwankwo, E. and Edino, S. (2014) Seasonal Variation and Risk Factors Associated with Surgical Site Infection Rate in Kano, Nigeria. Turkish Journal of Medical Sciences, 44, 674-680. https://doi.org/10.3906/sag-1305-47

[15] Nadlaou, B., Abdelsalam, T., Guelmbaye, N., Clement, K.H. and Nicolas, B. (2016) Prevalence Multi-Resistant Bacteria in Hospital N'djamena, Chad. Chemotherapy Open Access, 4, 4. https://doi.org/10.4172/2167-7700.1000170

[16] Pear, S.M. (2007) Patient Risk Factors Best Practices for Surgical Site Infection Prevention. Education \& Training, March, 56-64.

[17] Rakotoarimanana, R. (2009) Nutrition et infection. Revue Médicale Suisse, 5, 19751978.

[18] Haridas, M. and Malangoni, M.A. (2008) Predictive Factors for Surgical Site Infection in General Surgery. Surgery, 144, 496-503.

https://doi.org/10.1016/j.surg.2008.06.001

[19] Richard, T., Buttafuoco, F., Vanhaeverbeek, M. and Cherifi, S. (2018) Association between Diabetes Mellitus and Infection: Which Evidence for a Causal Role of Hyperglycemia? Revue Medicale de Bruxelles, 39, 495-504. https://doi.org/10.30637/2018.17-057

[20] Merzougui, L., Marwen, N., Hannachi, H., Asma, M., Elhaj, O.B., Waddah, M. and Fatnassi, R. (2018) Incidence et facteurs de risque de l'infection du site opératoire après césarienne dans une maternité de tunisie. Santé Publique, 30, 339-347. 
https://doi.org/10.3917/spub.183.0339

[21] World Health Organization (2016) Global Guidelines for the Prevention of Surgical Site Infection. WHO Document Production Services, Geneva.

https://www.who.int/gpsc/ssi-prevention-guidelines/en/

[22] Guohua, X., Cheng, K., Li, J., Kong, Q., Wang, C. and Nanyuan, Y. (2015) Risk Factors for Surgical Site Infection in a Teaching Hospital: A Prospective Study of 1,138 Patients. Patient Preference and Adherence, 9, 1171-1177. https://doi.org/10.2147/PPA.S86153

[23] Keita, A.K., Doumbouya, N., Sow, M.S., Konaté, B., Dabo, Y., Panzo, D.A. and Keita, M. (2016) Prévalence des infections nosocomiales dans deux hôpitaux de Conakry (Guinée). Santé Publique, 28, 251. https://doi.org/10.3917/spub.162.0251

[24] Garba, I., Mohamed, A.W., Younssa, H., Habibou, D. and Aristote, H.-M. (2018) L'Infection du Site Opératoire en Chirurgie Ortho-Traumatologique Propre au CNHU-HKM de Cotonou. Health Sciences and Disease, 19, 108-111. 